\title{
Invasive ductal carcinoma within fibroadenoma and lung metastases
}

This article was published in the following Dove Press journal:

International Journal of General Medicine

30 December 201I

Number of times this article has been viewed

\section{Zuhair Abu-Rahmeh' \\ William Nseir ${ }^{2}$ \\ Inna Naroditzky ${ }^{3}$ \\ 'Radiology Department, ${ }^{2}$ Department of Internal Medicine, Holy Family Hospital, Nazareth, \\ ${ }^{3}$ Pathology Department, Rambam \\ Medical Center, Haifa, Israel}

\begin{abstract}
Fibroadenomas are one of the most common benign tumors of the breast. Malignant transformation from fibroadenoma to cancer is rare. We present a case of an invasive ductal carcinoma within an otherwise benign fibroadenoma with lung metastasis in a 69-year-old woman.
\end{abstract}

Keywords: benign tumor, invasive ductal carcinoma, lung metastasis

\section{Introduction}

Fibroadenoma of the breast is relatively frequent. Women can present with fibroadenoma at any age, but the peak incidence is in the second and third decades of life. Fibroadenoma is the most common benign breast tumor in adolescent girls and young women. ${ }^{1}$ Growth of fibroadenoma is stimulated by estrogen, progesterone, pregnancy, and lactation, ${ }^{2,3}$ often presents as a palpable mass measuring up to $3 \mathrm{~cm}$, and may undergo atrophic changes in menopause.

Fibroadenoma is a biphasic tumor composed of a stromal and an epithelial component. Although, fibroadenoma is generally considered benign, there is evidence for an association with an increased risk of invasive breast cancer. ${ }^{4}$ Furthermore, progression of the epithelial component to carcinoma in situ and invasive carcinoma has been documented in the literature..$^{5-8}$ Malignant transformation from fibroadenoma to cancer is rare. Moreover, the risk of developing breast cancer was found to be higher in patients with complex fibroadenoma. ${ }^{5}$ The mean age reported for patients with carcinoma arising in fibroadenoma is in the fifth decade, almost 20 years older than the peak age of women diagnosed with simple fibroadenoma. Cheatle and Culter were the first to describe a carcinoma arising in a fibroadenoma.

Since there are no definite clinical or radiological criteria for diagnosing carcinoma arising in a fibroadenoma, histopathological examination should be performed routinely to rule out malignancy in cases of nonsimple fibroadenoma.

\section{Case presentation}

A 69-year-old woman having one first-degree family member with breast cancer presented to the breast imaging unit for screening mammography. She had had screening mammography every 2 years since 1997, with multiple bilateral benign breast masses detected. In 2011, one of the masses in the left breast changed in diameter from $3 \mathrm{~cm}$ on mammography done in February 2010 (Figure 3) to $5 \mathrm{~cm}$ diameter in mammography done in May 2011 (Figure 2). Ultrasonography revealed a well-circumscribed homogeneous hypoechoic mass $5 \mathrm{~cm}$ in diameter (Figure 1). An ultrasound-guided
Correspondence: Zuhair Abu-Rahmeh Department of Radiology,

Holy Family Hospital,

Box 8, Nazereth, Israel

Tel +97246508967

Fax +97246508916

Email z.abu-rahmeh@hospitalnazareth.org 


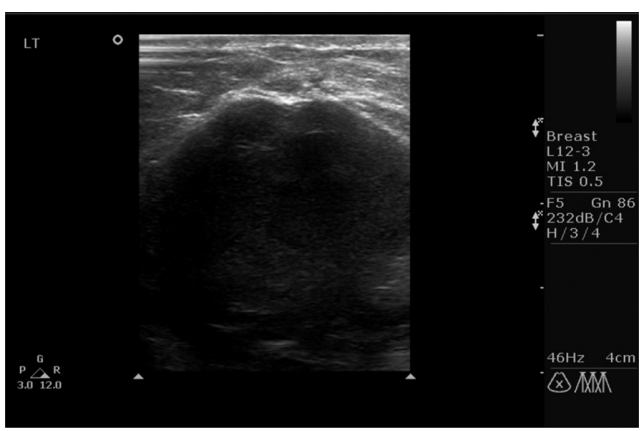

Figure I Ultrasonography revealed a well-circumscribed homogeneous hypoechoic mass $5 \mathrm{~cm}$ in diameter.

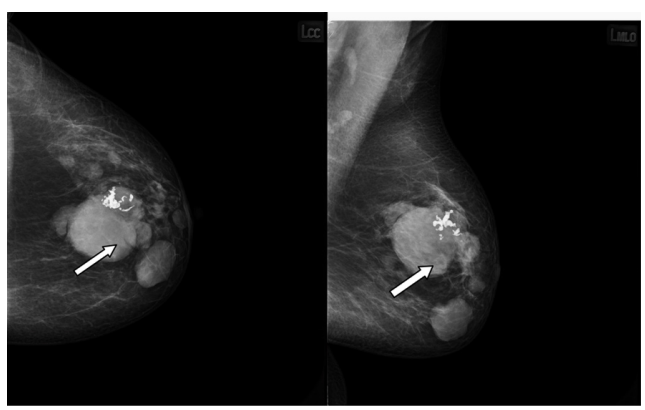

Figure 2 Mammography in May $201 \mathrm{I}$ revealed well-defined, rounded, and oval masses, some with coarse calcifications and the largest being $5 \mathrm{~cm}$ in diameter (white arrow).

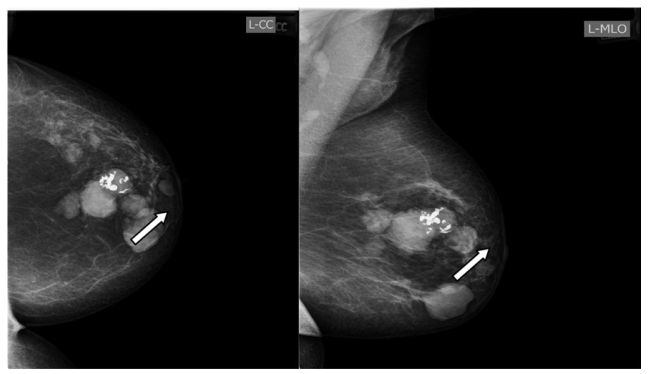

Figure 3 Mammography in February 2010 revealed well-defined, rounded and oval masses, some with coarse calcifications the largest being $3 \mathrm{~cm}$ in diameter (white arrow).

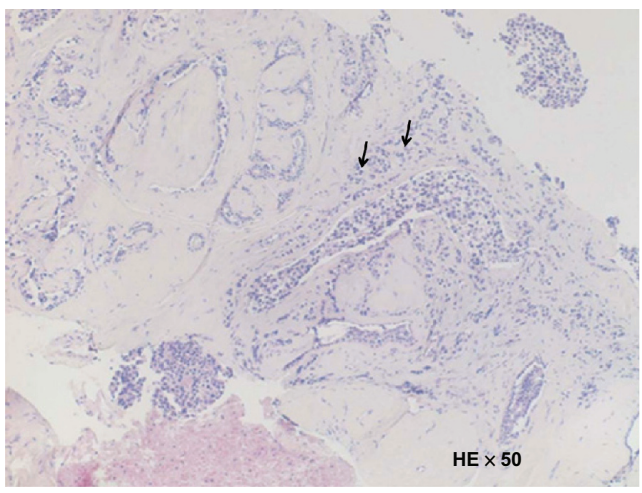

Figure 4 Within the typical fibroadenoma, irregular groups of invasive carcinoma cells are seen in the stroma (arrows). Hematoxylin and eosin $(\mathrm{HE}) \times 50$.

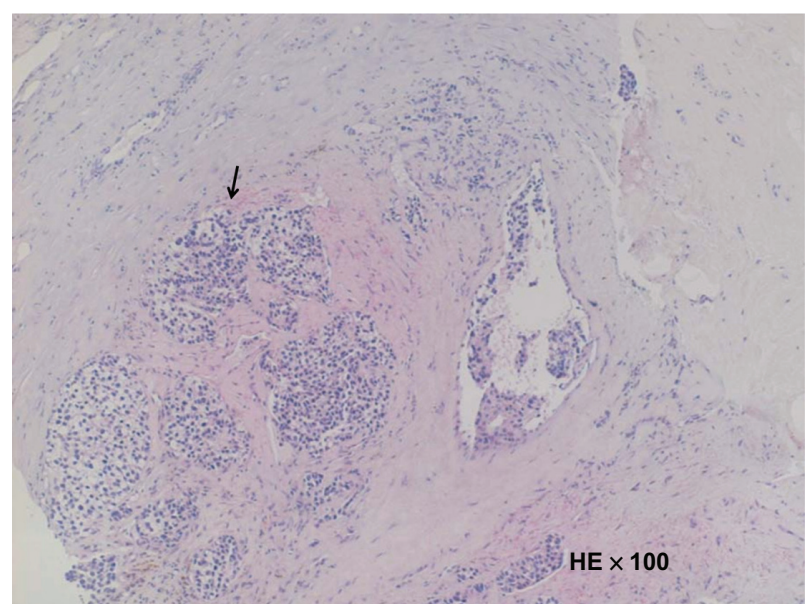

Figure 5 Nests of invasive carcinoma (arrow). Hematoxylin and eosin $(\mathrm{HE}) \times 100$.

core biopsy was taken and examination of the mass revealed a fibroadenoma with a focus of invasive ductal carcinoma that was completely confined within the fibroadenoma. Computed tomography of the chest showed two metastatic nodules in the right lung. Abdominal ultrasound and laboratory findings were unremarkable. Microscopy revealed fibroadenoma with many foci of invasive duct carcinoma (Figure 4). Staining of the myoepithelium around tumoral foci with $\mathrm{CD} 10$ and actin was negative (Figures 5 and 6 ).

\section{Discussion}

Fibroadenomas are common benign lesions of the breast that usually present as a single breast mass in young women. Simple fibroadenomas have a reported incidence of $7 \%-13 \%$ in women from adolescence through the mid $20 \mathrm{~s}$ who present to specialty clinics. ${ }^{1}$ The prevalence of simple

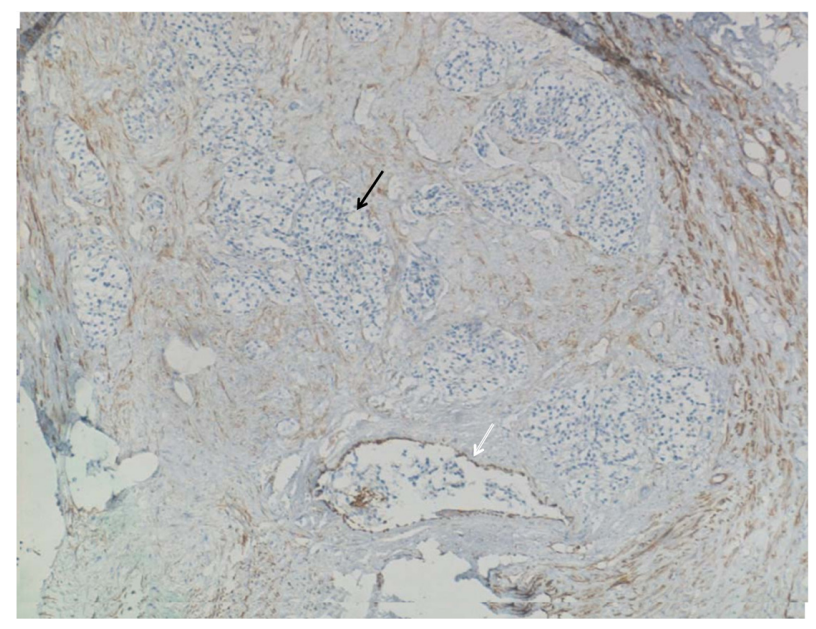

Figure 6 Myoepithelial cells are absent in invasive carcinoma (black arrow), and myoepithelial cells are preserved in fibroadenoma structures (white arrow). Calponin immunostain $\times 100$. 
fibroadenomas in this age group in the general population is reported to be $2.2 \%$ and is said to decrease with increasing age. $^{7}$ The incidence of carcinoma within fibroadenoma is reported to be $0.1 \%-0.3 \%$ in a screened population, with

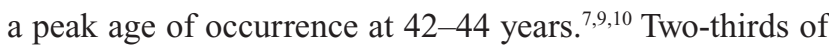
carcinomas within fibroadenoma are lobular and one-third are ductal or mixed ductal and lobular; lobular carcinoma in situ and ductal carcinoma in situ has an approximately equal frequency. ${ }^{2,4}$

Complex fibroadenomas and proliferative disease adjacent to fibroadenoma are associated with a slight increase in the risk of breast cancer. ${ }^{2,4,11}$ Invasive ductal carcinoma within fibroadenoma is rare. ${ }^{12-15}$ Although malignant transformation of a fibroadenoma is infrequent, the presence of this tumor in a woman with a positive family history of breast cancer may have greater clinical importance than a fibroadenoma arising in a woman with no additional risk factors. Detection of malignancy developing within a fibroadenoma can be difficult. Clinical and radiological signs may be masked. Physicians should be aware of the potential for progression of breast fibroadenoma, particularly in women with a known BRCA mutation or a strong family history. This case report supports the need for a more aggressive diagnostic approach towards solid benign-appearing breast lesions in women with a strong positive family history of breast and/ or ovarian cancer.

\section{Conclusion}

Despite the low percentage of carcinoma occurring within fibroadenoma we consider that each lump that changes in diameter or echogenicity should be seriously managed; extirpation and histological examination are recommended. Special caution is warranted in women older than 35 years presenting with a fibroadenoma more than $2 \mathrm{~cm}$ in diameter. The possibility of carcinoma originating within fibroadenoma should be considered in cases of lung metastases in women with known fibroadenoma.

\section{Disclosure}

The authors report no conflicts of interest in this work.

\section{References}

1. Greenberg R, Skornick Y, Kaplan O. Management of breast fibroadenomas. J Gen Intern Med. 1998;13:640-645.

2. Kujiper A, Preisler-Adams SS, Rahusen FD, Gille JJP, Wall E, van Diest PJ. Multiple fibroadenomas harboring carcinoma in situ in a woman with a family history of breast/ovarian cancer. J Clin Pathol. 2002;55:795-797.

3. Kujiper A, Mommers EC, Van der Wall, Van Diest PJ. Histopathology of the fibroadenomas of the breast. Am J Clin Pathol. 2001;115: 736-742.

4. Dupont WD, Page DL, Parl FF, et al. Long term risk of breast cancer in women with fibroadenoma. N Engl J Med. 1994;331:10-15.

5. Buzanowski-Konakry K, Harrison EG Jr, Payne WS. Lobular carcinoma arising in fibroadenoma of the breast. Cancer. 1975;35:450-456.

6. Ozello L, Gump FE. The management of patients with carcinomas in fibroadenomatous tumours of breast. Surg Gynecol Obstet. 1985;160: 99-104.

7. Dechens L, Jacob S, Fabia J, Christen A. Beware of breast fibroadenomas in middle aged women. Can J Surg. 1985;28:372-374.

8. Iyengar KR, Peh SC, Yip CH, Vijayananthan A. Infiltrating duct carcinoma within a fibroadenoma. Indian J Cancer. 2009;46:244-246.

9. Abe H, Hanasawa K, Naitoh H, Endo Y, Tani T, Kushima R. Invasive ductal carcinoma within a fibroadenoma of the breast. Int J Clin Oncol. 2004;9(4):334-338.

10. Diaz NM, Palmer JO, McDivitt RW. Carcinoma arising within fibroadenomas of the breast; a clinicopathologic study of 105 patients. Am J Clin Pathol. 1991;95:614-622.

11. Azzopardi JG. Problems in breast pathology. In: Bennington JC, editor. Major Problems in Pathology. London, UK: WB Saunders; 1979.

12. Pick PV, Lossifides IA. Occurrence of breast carcinoma within a fibroadenoma. Arch Pathol Lab Med. 1984;108:590-594.

13. Abe H, Hanasawa K, Naitoh H, Endo Y, Tani T, Kushima R. Invasive ductal carcinoma within a fibroadenoma of the breast. Int J Clin Oncol. 2004;9:334-338.

14. Stafyla V, Kotsifopoulos N, Grigoriades K, Kassaras G, Sakorafas GH. Lobular carcinoma in situ of the breast within a fibroadenoma. A case report. Gynecol Oncol. 2004;94:572-574.

15. Kurosumi M, Itokazy R, Mamiya Y, et al. Invasive ductal carcinoma with a predominant intraductal component arising in a fibroadenoma of the breast. Pathol Int. 1994;44(12):874-877.

\section{Publish your work in this journal}

The International Journal of General Medicine is an international, peer-reviewed open-access journal that focuses on general and internal medicine, pathogenesis, epidemiology, diagnosis, monitoring and treatment protocols. The journal is characterized by the rapid reporting of reviews, original research and clinical studies across all disease areas.

\section{Dovepress}

A key focus is the elucidation of disease processes and management protocols resulting in improved outcomes for the patient.The manuscript management system is completely online and includes a very quick and fair peer-review system. Visit http://www.dovepress.com/ testimonials.php to read real quotes from published authors. 